\title{
A ÉTICA E O FUTURO DA HUMANIDADE: CONSIDERAÇÕES CRÍTICAS SOBRE EDUCAÇÃO AMBIENTAL
}

\author{
Pedro Goergen ${ }^{1}$
}

Resumo: $\mathrm{O}$ argumento central deste artigo defende a ideia segundo a qual a educação ambiental, embora importante e imprescindível, não representa a solução dos problemas ambientais que hoje ameaçam a vida humana, animal e vegetal. $\mathrm{O}$ modo de relação agressivo e destruidor entre o homem e a natureza é parte intrínseca à razão moderna, utilitarista e instrumental. Os problemas ambientais decorrem, portanto, de uma postura civilizatória em termos epistêmicos, éticos e estéticos, assumidos na modernidade. Devido aos limites de espaço e tempo, o texto se concentra sobre a dimensão ética. A partir desta constatação, argumentase que soluções abrangentes e definitivas dos problemas ambientais dependem da instituição de uma nova consciência civilizatória. Uma consciência civilizatória que inclua nos cálculos de suas estratégias de desenvolvimento o conceito de limite como condição essencial à preservação da vida e do futuro da natureza e da humanidade.

Palavras-chave: Educação ambiental. Meio ambiente. Ética. Civilização.

\section{ETHICS AND THE FUTURE OF HUMANKIND: CRITICAL CONSIDERATIONS ON ENVIRONMENTAL EDUCATION}

Abstract: The central argument of this paper supports the idea that although the environmental education is important and indispensable it does not represent the solution of environmental problems that threaten the human, animal vegetative life nowadays. The mode of aggressive and destructive relationship between man and nature is intrinsic part of a modern, utilitarian and instrumental reason. The environmental problems therefore arise from a civilizing posture in epistemic, ethical and aesthetic terms assumed in modernity. Because of the limits of space and time, the text focuses on the ethical dimension. From this perspective it is argued that comprehensive and definitive solutions to environmental problems depend on the establishment of a new civilizing consciousness. A civilizing awareness that includes in the calculations of its strategies of the concept of limit as essential to the preservation of life and the future of nature and humanity condition.

Keywords: Environmental Education. Environment. Ethic. Civilization.

\footnotetext{
${ }^{1}$ Doutor em filosofia e educação pela Universidade de Munique; Pós Doutor pela Universidade de Bochum (Alemanha); Pós-doutorado pelo Instituto Max Planck de Berlin. Professor Titular (aposentado) da Unicamp; Professor Titular da Universidade de Sorocaba. Rua do Parque, 420; CEP 13.100-057 Campinas - SP - Brasil. pedro.goergen@ hotmail.com
} 


\section{LA ÉTICA Y EL FUTURO DE LA HUMANIDAD: CONSIDERACIONES CRÍTICAS SOBRE EDUCACIÓN AMBIENTAL}

Resumen: El argumento central de este artículo apoya la idea según la cual la educación ambiental, si bien importante y imprescindible, no es la solución de los problemas ambientales que, hoy, amenazan la salud humana, animal y vegetal. El modo de la relación, agresiva y destructiva, entre el hombre y la naturaleza, es intrínseco a la razón moderna, utilitarista y instrumental. Por lo tanto, los problemas ambientales surgen de una postura civilizadora en los términos epistémicos, éticos y estéticos asumidos en la modernidad. Debido a las limitaciones de espacio y tiempo, el texto se centra en la dimensión ética. A partir de este hallazgo, se argumenta que las soluciones integrales y definitivas a los problemas ambientales dependen de la creación de una nueva conciencia de civilización. Una conciencia que incluya, en el cálculo de sus estrategias de desarrollo, el concepto de límite como algo esencial para la preservación de la vida y el futuro de la naturaleza y de la humanidad.

Palabras clave: Educación ambiental. Medio Ambiente. Ética. Civilización.

\section{Introdução}

Reuniões de cúpula internacionais, encontros, seminários, palestras e pesquisas promovidos por governos, grupos econômicos, universidades, organizações não governamentais e outras instituições, públicas e privadas, mostram o quanto tem crescido, nas últimas décadas, a preocupação com a questão ambiental. Não é preciso dizer que esse interesse não se origina apenas do nobre altruísmo de cuidado com a natureza, mas do impacto dos riscos decorrentes das intervenções agressivas e predadoras na natureza, potencializadas pelo desenvolvimento da ciência e tecnologia. A poluição da água e do ar; a devastação das florestas; a destruição da camada de ozônio; o aumento da temperatura; a produção de detritos; o uso de pesticidas, herbicidas e biocidas, e o esgotamento das fontes de energia natural tornam a vida de homens, animais e plantas, cada vez mais difícil. Na opinião de muitos autores das mais diferentes áreas do conhecimento, são eminentes os riscos de um colapso ambiental de grandes senão de fatais proporções. Multiplicam-se as vozes que falam da sociedade de risco (BECK, 2008) da catástrofe (ZIZEK, 2012), do desprezo (HONNETH, 2011), da barbárie (HENRY, 2012). Trata-se de um problema civilizatório que ameaça o futuro da própria humanidade.

Dentre as tantas iniciativas, acordos, compromissos, pesquisas, leis, sanções, campanhas de conscientização, a educação ambiental, formal ou informal, é considerada estratégia imprescindível para reverter o quadro de destruição e medo ao qual as pessoas e a própria humanidade estão expostas. Argumenta-se que é preciso reeducar as crianças, os jovens e os adultos de modo que, conscientes dos riscos ambientais, passem a ter cuidado com a natureza, evitando, assim, a poluição e a destruição no futuro. Imagina-se que essa mudança de atitude seja suficiente para transformar a relação de agressão numa espécie de relação paz $e$ amor entre o homem e a natureza. Estaria assegurada, assim, a convivência harmoniosa entre os homens e o ambiente, e garantida a preservação das condições naturais da terra, da água e do ar, de tal sorte que o mundo 
vegetal, animal e, em consequência, também o mundo humano teriam condições de vida saudável no futuro.

O que pretendo questionar, na reflexão que se segue, é que, embora imprescindível e fundamental, a educação ambiental não alcança resolver os problemas de fundo inerentes ao próprio sistema civilizatório moderno. Não resultam suficientes pequenas intervenções no final de uma enorme cadeia de posturas epistêmicas, éticas e econômicas para corrigir problemas sistêmicos, inerentes ao modelo de desenvolvimento assumido ao longo dos últimos duzentos ou trezentos anos. Mesmo não partilhando do pessimismo de James Lovelock (2010, p.39), parece-me importante lembrar seu alerta frente aos riscos do ambientalismo romântico:

\begin{abstract}
Quando sou advertido de que meu pessimismo desestimula aqueles que melhorariam sua pegada de carbono ou fariam bons trabalhos como plantar árvores, lamento que eu considere que tais tentativas são, na melhor das hipóteses, bobagem romântica, ou, na pior, hipocrisia. Hoje existem agências que permitem que passageiros aéreos plantem árvores para compensar o dióxido de carbono que seu avião adiciona ao ar sobrecarregado. Têm a mesma função das indulgências outrora vendidas pela Igreja Católica aos pecadores ricos para compensar o tempo que de outra forma passariam no purgatório.
\end{abstract}

A ideia que pretendo defender é que a correção do projeto de desenvolvimento, cujos efeitos assustam a todos que se preocupam com o presente e o futuro da humanidade, deve ser de natureza mais ampla e profunda em termos epistemológicos, éticos e estéticos. Quanto ao aspecto epistemológico, Henrique Leff (2010, p.17) nos diz que a crise ambiental é, sobretudo, a crise do pensamento não apenas das ciências, mas da própria cultura ocidental. "O saber ambiental ultrapassa o campo do conhecimento científico para se inserir na ordem da racionalidade". Quanto à ética, Hans Jonas (1984, p.15) lembra que "com a ampliação de nosso poder, transformou-se também a essência do comportamento humano; e, como a ética tem a ver com o comportamento, é necessário concluir que a natureza transformada do comportamento humano requer, também, uma transformação da ética". O finalmente livre Prometeu, ao qual a ciência atribui forças nunca conhecidas e a economia impulsos desimpedidos, clama por uma ética que, por livres freios, impeça que seu poder se torne a desgraça do ser humano. Por último, com referência à estética, Edgar Morin (2013, p.342-343) fala da estética como a capacidade de vermos e nos relacionarmos com a natureza enquanto nosso cosmo, cidade ou habitat considerados um fim em si mesmos e, portanto, livres da razão instrumental, se preocupa apenas com a transformação, uso e o consumo.

\footnotetext{
A relação estética não deve ser considerada um luxo. Ela nos remete ao melhor, ao mais sensível de nós mesmos. Ela nos envia uma mensagem de autenticidade a respeito de nossas relações com os outros, com a vida, com o mundo. Ela nos propicia maravilhamentos que são momentos de felicidade. Essa capacidade de se maravilhar não pode senão nos ajudar a resistir à crueldade desse mundo e à barbárie humana.
}

Pretendo aprofundar cada uma dessas três dimensões como espaços nos quais radicam os problemas ecológicos, defendendo que é ali, na raiz, o lugar onde a reconciliação entre o homem e a natureza pode ser alcançada. Mas isso exige um trabalho de maior fôlego do qual não é possível dar conta no breve tempo de uma conferência. Faço, então, um recorte, limitando-me a apresentar uma reflexão sobre as 
implicações éticas da relação instrumental entre homem e natureza, deixando os aspectos epistemológicos e éticos para outra oportunidade.

As intervenções educativas parcelares, tópicas, disciplinares, embora importantes permanecem periféricas e de efeito cosmético se não forem entendidas como parte de um esforço de mudança e reorientação civilizatória. Essas dimensões mais profundas, traduzidas, concretamente, no paradigma civilizatório ambientalmente agressivo e destruidor precisam ser mudadas. Segundo Leff (2003, p.8), "a crise ambiental, entendida como crise de civilização, não pode encontrar uma solução pela via da racionalidade teórica e instrumental que constrói e destrói o mundo". E não é preciso dizer que é nesse nível que ocorrem as mais fortes dificuldades e resistências como mostram os difíceis e estéreis debates dos tratados, convenções, protocolos, assembleias e grandes cúpulas internacionais, realizados desde o final da década de 1950.

Não só todo o sistema econômico liberal-capitalista se baseia na exploração agressiva do meio ambiente como também toda a racionalidade moderna, que deu origem à ciência e tecnologia, parte do pressuposto de que a exploração e domínio da natureza são o caminho para um futuro radiante e feliz. Embasado na mecânica da utilidade do interesse individual, o pensamento econômico da epistemologia mecanicista ocidental, voltada à produção e ao consumo, torna-se um referencial fechado e autorreferente para o qual parece não haver alternativa. Daí que o mal, radicado no cerne da própria cultura capitalista ocidental, não pode ser superado pela eliminação de suas manifestações aparentes. O que na cultura germina, só na cultura pode ser mudado.

Georgescu-Roegen, (2012, p.131) expressou isso da seguinte forma:

[...] nenhum programa ecológico razoável deve ignorar um fato fundamental. É o fato de que, conforme tudo o que sabemos da luta pela vida em geral, o homem não se deixará abater se, para isso, tiver de poupar seus concorrentes, inclusive os seres humanos futuros, porque é pressionado por suas necessidades naturais e culturais. Em biologia, não há lei alguma que afirme que uma espécie deva defender a existência das outras à custa da sua.

Isso significa que a postura ecologicamente correta não é congênita ao ser humano, mas sim cultural, ou seja, é uma postura aprendida e assumida conscientemente.

Como se percebe, estamos falando de ética, mas de uma ética cujo alcance não se reduz à sustentabilidade da vida humana, mas se abre para a sustentabilidade da vida como um todo. Se Hobbes (1588-1697) vivesse hoje, talvez dissesse que os homens são, por natureza, agressivos não só em relação aos seus semelhantes, mas também em relação ao meio ambiente. Nesse sentido, podemos também imaginar que Hobbes haveria de sugerir um contrato de convivência não só entre humanos, mas igualmente entre o homem e a natureza. De fato, foi Rousseau (1712-1774) quem, um século mais tarde, com sua inovadora admiração pela natureza, abriu as primeiras pistas nesse sentido.

Para detalhar um pouco a questão da racionalidade ocidental moderna, portadora da estratégia do domínio e da exploração da natureza, vou retornar ao já mencionado matemático e economista romeno Georgescu-Roegen. Aliás, um autor considerado persona non grata em alguns círculos científicos em função de sua tese do decrescimento, contrária aos interesses do desenvolvimentismo sistêmico. Para ele, a equação entre crescimento permanente e consumo de energia material não é sustentável; 
ao contrário, a sustentabilidade futura pressupõe, necessariamente, o decrescimento. Trata-se de uma crítica radical ao atual modelo científico/econômico, crítica essa inaceitável para a maioria dos seus operadores.

Grinewald e Rens (2012, p.21-22), autores do prefácio ao polêmico livro "Decrescimento", de Georgescu-Roegen, resumem assim seu argumento central:

\begin{abstract}
A partir da revolução termoindustrial do Séc. XIX, o extraordinário crescimento das nações ditas modernas ou desenvolvidas é tributário de uma excepcional abundância mineral, inseparável do fantástico progresso científico e técnico da civilização capitalista ocidental. Acreditar, entretanto, que essa abundância não tem limites nem consequências ecológicas é uma ilusão do pensamento linear, da mitologia moderna do progresso e do desenvolvimento.
\end{abstract}

Se é verdade que todos os seres vivos usam energia para manter-se vivos, é verdade, também, que "todos os organismos vivem de baixa entropia sob uma forma encontrada imediatamente no ambiente. O homem é a mais flagrante exceção: cozinha a maior parte de seus alimentos e também transforma os recursos naturais em trabalho mecânico ou em diferentes objetos de utilidade", causando uma severa perda de energia (GEORGESCU-ROEGEN, 2012, p. 61).

Esse déficit de energia foi desconsiderado quando os economistas, na sua representação do processo econômico, ignoraram os limites do meio ambiente natural.

\begin{abstract}
As realizações sem precedentes da revolução industrial haviam impressionado tão bem a todos, quanto ao que o homem poderia fazer com a ajuda da tecnologia, que a atenção geral se confinou sobre a fábrica. A profusão de descobertas científicas espetaculares ocasionadas pelos novos meios técnicos reforçou a admiração geral pelo poder da tecnologia. Ela induziu também os intelectuais a superestimar e, finalmente, a exaltar os poderes da ciência. Evidentemente, colocada em tal pedestal, ninguém poderia nem mesmo conceber a existência de obstáculos reais inerentes à condição humana (GEORGESCU-ROEGEN, 2012, p. 64).
\end{abstract}

Os conhecidos efeitos entrópicos do uso da energia material não reduziram o encantamento com a ciência e a tecnologia. Em todo o mundo intelectual surgiu uma disposição mental favorável à ideia de que a perda de energia e a correlata produção de resíduos ocorriam em um círculo fechado, equilibrado e, portanto, inesgotável.

Vejamos isso um pouco mais de perto. $O$ ser humano depende, fundamentalmente, de duas fontes de energia. De um lado, a energia solar e, de outro, a energia material, armazenada nas entranhas da terra. A energia solar é um fluxo disponível para o uso, sem risco de esgotamento, tanto porque, segundo cálculos de cientistas, o sol ainda brilhará com a mesma intensidade por mais cinco bilhões de anos, quanto também porque não é possível antecipar o uso da energia solar das gerações posteriores. Contrariamente, a energia-matéria, se usada indiscriminadamente, se esgotará e faltará no futuro. Em síntese, a energia solar é infinita em termos de capacidade de consumo humano, enquanto a energia terrestre é limitada. Se usada de uma só vez, toda a energia terrestre não representaria mais que uns poucos dias de energia solar. As previsões indicam que, se o consumo seguir no ritmo atual, várias fontes de energia terrestre, essenciais ao modelo econômico atual, se esgotarão em poucas décadas. 
Do ponto de vista técnico, o ser humano dispõe, hoje, de todos os recursos para exercer a ditadura do presente sobre o futuro. Prevalecendo a visão linear e segmentada da história, aliada ao consumo indiscriminado de energia, a exuberância do presente pode representar a carência e, no limite, a inviabilidade da vida futura. Esgotadas as reservas energéticas, essenciais ao funcionamento do atual modelo de desenvolvimento, o que poderá ser feito? Descobrir novas fontes de energia? Mas, em que medida e por quanto tempo isso seria possível? Para essas perguntas ainda não há respostas plausíveis, deixando-nos numa incerteza que ameaça, qual espada de Dâmocles, a vida futura da humanidade.

Georgescu-Roegen (2012, p.67) lembra que "de um lado, em virtude do progresso espetacular da ciência, o homem chegou a um nível quase miraculoso de desenvolvimento econômico. Por outro lado, esse desenvolvimento obrigou o homem a elevar sua retirada de recursos terrestres a um grau assombroso..." Diante disso, Kenneth Boulding, usado como epígrafe por Morin (2013), diz que "qualquer um que acredite que um crescimento exponencial pode durar para sempre num mundo finito ou é um louco ou um economista".

Menos radical que a tese do decrescimento tout court, Morin (2013, p.28) defende que "a ideia fixa de crescimento deveria ser substituída por um complexo que comportasse diversos crescimentos, diversos decrescimentos, diversas estabilizações". Porém, o grande dilema diante do qual nos encontramos se resume no seguinte: nosso sistema econômico, para sustentar-se, necessita crescer; para crescer precisa consumir sempre mais, e o consumo crescente é absolutamente insustentável ao longo prazo. Esse dilema é o enigma da esfinge contemporânea: decifra-me ou eu te devoro.

Não há como não reconhecer os grandes benefícios decorrentes do desenvolvimento industrial, mas é bastante seguro também que este desenvolvimento chegará, no futuro, a um impasse de sobrevivência humana em função dos limites da energia material disponível. Para o dilema entre os interesses da humanidade atual e os interesses da humanidade futura ainda não se vislumbra solução. Eis o paradoxo do desenvolvimento baseado no crescimento infinito.

Mesmo sabendo disso, é difícil imaginar que o homem de hoje se disponha, pelo bem das gerações futuras, a reduzir suas expectativas de benefícios e confortos derivados do crescimento incessante. $\mathrm{E}$ isto está intrinsecamente ligado ao paradigma epistêmico, ético e estético assumido na modernidade. Sendo assim, não resta alternativa senão conscientizar o homem a respeito desse paradoxo entrópico da espécie humana. Para Morin (2013, p.103):

[...] as vias para se responder à ameaça ecológica não são apenas técnicas; elas necessitam, prioritariamente, de uma reforma do nosso modo de pensar para englobar a relação entre a humanidade e a natureza em sua complexidade e conceber as reformas de civilização, as reformas de sociedade, as reformas de vida.

O desafio a ser vencido é o da disjunção entre o humano e o natural, "resultado do crescimento do racionalismo técnico ocidental e da pregnância do antropocentrismo judeu-cristão" (MORIN, 2013, p.103). A natureza e o próprio homem convertem-se em mera objetividade e, nas palavras de Adorno e Horkheimer (1985, p.24), "o preço que os homens pagam pelo aumento de seu poder é a alienação daquilo sobre o que exercem o poder. O esclarecimento comporta-se com as coisas como o ditador se comporta com os homens. Este os conhece na medida em que pode manipulá-los". 
Parece não restar alternativa para a humanidade senão a revisão profunda da utópica ilusão do crescimento infinito, baseado no domínio e na exploração. Trata-se de ajustar o comportamento humano de modo a aproximá-lo, da melhor forma possível, a um estado de uso equilibrado entre a infinita energia solar e a limitada energia terrestre. Para tanto, parece incontornável um giro civilizatório, em suas dimensões epistêmica, ética e estética. Não podemos esquecer que integramos com a natureza uma comunidade de destino, sendo que, ao contrário do que imagina a prepotência humana, a humanidade é a parte mais frágil dessa comunidade. Mesmo que o homem destrua toda a vida existente sobre a terra, haverá bilhões de estrelas que sequer se darão conta disso.

Esse cenário de crise vital nos coloca frente à exigência de uma profunda mudança da postura humana. Ao lado dos aspectos racionais e estéticos, a serem tratados em outro contexto, destaca-se a adoção de um novo paradigma ético que leve em conta, para o bem da vida, as novas relações entre saber e poder. Na mesma medida em que se amplia o poder de intervenção do homem sobre o meio e a vida, a sobrevivência exige novos parâmetros de julgamento e responsabilidade ética. Georgescu-Roegen (1012, p.129-30) alerta que:

[...] temos um único meio de proteger as gerações futuras, pelo menos do consumo excessivo dos recursos enquanto os temos em abundância. É nos reeducarmos a fim de termos um pouco de simpatia pelos seres humanos futuros da mesma forma que nos preocupamos com o bem-estar de nosso 'próximo' contemporâneo. Isto não significa que a nova orientação ética seja coisa fácil.

Diante do enorme peso desse processo avassalador, que avança célere, comprometendo o equilíbrio natural, não é suficiente depositar todas as nossas esperanças na educação ambiental. Sua importância é incontestável, mas somente se for entendida e praticada como parte de um processo maior e mais profundo de transformação. Enquanto permanecer envolta nas brumas rosadas de um romantismo quase bucólico, como às vezes ocorre, a educação ambiental pode, até mesmo, exercer um indesejado papel ideológico. A crença que a educação ambiental pode neutralizar os riscos e a barbárie autoriza o sistema a prosseguir na sua marcha de agressão e destruição. Na medida em que, tomada isoladamente, a educação ambiental estimula a falsa ideia de que os problemas ambientais são simples e de fácil solução, desvia-se a atenção das verdadeiras razões sistêmicas e civilizatórias que exigem interferências mais profundas e globais. Assim agem as próprias instituições como a ciência, a economia e até mesmo a educação, intrinsecamente envolvidas com o modelo de desenvolvimento predador, quando alardeiam suas iniciativas e seu engajamento ecológico.

Especialmente a escola, quando promove, cheia de boas intenções, a educação ambiental de crianças e jovens, repercute simultaneamente e a todo o instante a ideologia do consumismo. Ao mesmo tempo em que o consumismo, maior vilão da destruição ambiental, está incrustrado na tessitura curricular, nas relações entre gestores e docentes, entre escola e pais, a escola faz educação ambiental. Os próprios alunos são considerados clientes à busca de produtos (conhecimentos) como condição de acesso ao consumo, por sua vez, considerado a máxima condição de cidadania. O aporte à capacidade de consumir facultado pela educação é, inclusive, o critério de sucesso e de boa avaliação institucional, muito mais que formação cidadã e consciência crítica. É a 
esse currículo oculto, inerente aos pressupostos epistêmicos, éticos e estéticos, ao qual me refiro quando falo da necessidade de reformas profundas e civilizatórias.

A julgar pela literatura disponível (JONAS, 1984; BECK, 2008; LOVELOCK, 2010; HENRY, 2012; ZIZEK, 2012; GEORGESCU-ROEGEN, 2012; MORIN, 2013), está em formação um amplo consenso em torno da necessidade de mudanças profundas. Por outro lado, constatam-se fortes resistências em função dos interesses econômicos dos países, das corporações, do mercado, das instituições e das pessoas, todos temerosos de perderem suas vantagens econômicas, o poder e o conforto alcançados pelo desenvolvimento científico-tecnológico. Em tempos da glorificação do presente, da fruição do aqui e agora, poucos estão efetivamente dispostos a abrir mão das vantagens momentâneas em prol da vida de gerações futuras. Afinal, todo o sistema econômico capitalista se sustenta sobre a equação entre o crescimento ininterrupto e o uso predatório de energia. Apesar das evidências em contrário, prefere-se seguir acreditando que tudo funciona como um moto perpétuo, livre dos efeitos da lei da entropia. Essa conveniência encontra-se tão profundamente arraigada em nossas instituições e mentes que nem mesmo a educação ou a religião conseguem oferecer-lhe resistência.

Durante milênios, a relação entre o ser humano e o meio ambiente foi tranquila e despreocupada. Parecia haver um perfeito equilíbrio entre a exploração dos recursos naturais e a capacidade de recuperação da natureza. Mesmo após o incremento da capacidade humana de intervir na natureza pelos recursos da ciência e tecnologia, persistiu a imagem da natureza rica, pródiga e inesgotável, criada por Deus para ser dominada e explorada pelo homem. O que poderia mudar tal desígnio? Foram necessários sinais muito fortes para acender as luzes de alerta.

Embora a consciência ecológica, qual coruja de Minerva, esteja alçando voo somente ao entardecer, sabe-se que a árvore de frutos amargos, cujo gosto começamos a sentir, nasceu de sementes lançadas no início da modernidade. No seu Novum Organum, Francis Bacon (1561-1626) anuncia um novo método de conhecimento empírico, capaz de abrir as portas ao domínio e à exploração da natureza, acordando o ser humano de seu letárgico sono metafísico, para uma vida melhor, menos sofrida e mais confortável. A ciência associada à tecnologia se encarregaria de ampliar a capacidade de aproveitar os recursos naturais para melhorar, aqui e agora, as condições de existência.

De fato, iniciou-se a partir daí um prodigioso aumento do poder de intervenção do homem sobre a natureza e a exploração de seus recursos. O entusiasmo e a luz das conquistas ofuscava o olhar e escondia seu lado obscuro e sombrio. Só muito recentemente, quando o desequilíbrio entre o poder de intervenção e o esgotamento dos recursos materiais se tornou mais e mais evidente, surgiu a preocupação com o meio ambiente. Mesmo assim, o encanto do progresso, a vontade de poder, o prazer do conforto prevalecem sobre a necessidade do cuidado, do equilíbrio e da preservação.

Essa cega ambivalência entre o curto e o longo prazos, entre o hoje e o futuro, entre o individual e o social, entre o privado e o público, entre o direito de todos e o proveito de poucos, entre o uso e o abuso é o tema central da sobrevivência da humanidade. Desde os primórdios da história, os perigos e ameaças levaram os homens a se unirem para sobreviver. Sobre essa estratégia matricial de sobrevivência assenta-se toda a ética tradicional, independente das especificidades assumidas em diferentes contextos e momentos históricos. A luta pela sobrevivência individual e coletiva continua sendo a pedra de toque do agir humano, mas suas condições se alteraram profundamente, para o bem e para o mal. Para o bem porque as condições de vida são, hoje, melhores, pelo menos para boa parte da população. Para o mal porque os riscos e 
ameaças à sobrevivência de indivíduos e espécies inteiras também cresceu exponencialmente.

Não é exagerado dizer que qualquer esperança de futuro depende, hoje, do equilíbrio das relações entre o homem e seu meio. Se a razão de toda ética é a sobrevivência e a boa vida de todos, fica bastante evidente que a ética para os tempos atuais necessita ser ampliada, incluindo em seus cânones o meio ambiente, uma vez que sem sua preservação a sobrevivência é cada vez menos viável. Esta é a nova ética do cuidado (BOFF, 1999), do reconhecimento (HONNETH, 2003) e da responsabilidade (JONAS, 1984).

Nesses termos, a ética moderna centrada na vida em comunidade, conforme vemos nos contratos sociais sugeridos por Hobbes (1588-1679), Locke (1632-1704) e Rousseau (1712-1778) enfeixados no imperativo antropocêntrico, subjetivista e idealista de Kant (1724-1804) precisa ser repensada na perspectiva da vida como um todo bioantropológico. Ou seja, é preciso reconhecer que o homem só tem chance de sobrevivência se encontrar formas de con-vivência não apenas com os outros homens, mas também com a natureza. Daí a necessidade de uma nova ética, tal como vem sendo formulada sob o conceito de bioética (criado por Fritz Jahr, 1895-1953, em 1927). A bioética é o cuidado com a vida, tanto humana quanto animal e vegetal, com suas condições materiais, no presente e no futuro. Seu maior desafio é, precisamente, ultrapassar o individualismo e mesmo o antropocentrismo das éticas tradicionais.

A associação entre ciência e tecnologia teve efeitos danosos para a ecologia, que exigem o reequilíbrio entre seus interesses particular/imediatistas e os valores coletivo/futuristas, na perspectiva de uma nova compreensão bioética. O grande desafio desse projeto é a conciliação entre os interesses econômicos e os interesses humanitários. Tal conciliação torna-se tanto mais urgente quanto mais crescem os riscos decorrentes do atual modelo de desenvolvimento. Segundo Ulrich Beck (2008, p. 25), "o mundo já não pode controlar os perigos que a modernidade gera; mais exatamente, a fé que a sociedade moderna podia controlar os perigos que gera se desvanece (não por causa da demora ou da derrota da modernidade, senão que por causa de suas vitórias)".

São, precisamente, essas vitórias que agravam os riscos gerados pelo progresso cumulativo de ciência e tecnologia, evidenciando a necessidade urgente de um diálogo aberto e honesto entre a economia e a ecologia. Embora escreva desde uma perspectiva ético-religiosa, Carlos Josaphat (2010, p. 448) estabelece uma relação interessante e provocadora entre ecologia e economia numa referência que, mesmo um tanto longa, vale a pena lembrar:

Eco, oikos em grego, designa o habitat, a casa, a moradia. A economia surge primeiro, e se denomina como a administração doméstica, a norma que se encarna e se torna viva no 'ecônomo', que há de ser fiel e diligente para a prosperidade do lar, das coisas, dos bens e das pessoas da família. Mas alargando-se ao domínio a administrar, uma fazenda, um negócio, empresa, um conjunto de empresas, a economia se estreitou no seu significado, na atividade que a caracteriza, passando a designar primordial, senão exclusivamente, a prosperidade, o bom ou mesmo melhor rendimento em termos de dinheiro ou de bens materiais. Partindo da mesma raiz, a ecologia teria etimologicamente o mesmo significado: é o conhecimento cuidadoso do habitat. Mas a ecologia surge, precisamente, na época do auge e da predominância da economia para lhe suprir as falhas e corrigir os desmandos, indicando o mundo como oikos, como habitat da humanidade exigindo que seja cuidado com inteligência, competência e certo carinho. Esse conceito positivo do habitat, do ambiente vital, lembra a nomia, a boa norma de gerir 
e fazer prosperar o eco/oikos, o sistema ambiental em que se insere e de que deve cuidar a economia.

Esse equilíbrio entre economia e ecologia aponta para a necessidade de uma nova ética que abra caminho e assegure o reconhecimento não só do outro enquanto ser humano, conforme enfatiza Axel Honneth (2003), mas também do outro como ambiente, do outro como mundo e natureza. A tese de Honneth, referente à necessidade do reconhecimento do outro como forma de superação do comportamento agressivo, envolve também a mudança do comportamento destrutivo frente ao meio ambiente, por ser este a condição de vida do outro, hoje e no futuro.

Este alargamento da abrangência ética justifica-se por duas razões principais. Primeiro, porque é mister superar o antropocentrismo moderno que está na raiz de boa parte das combalidas relações entre os seres humanos e a natureza, gerando a sociedade de risco (BECK, 2008); segundo, porque a manipulação irresponsável da natureza representa uma agressão indireta aos seres humanos, visto que a vida humana necessita da natureza. Essa agressão é tanto mais lesiva quanto mais velada e de efeito retardado for, porque, assim, o ser humano (do futuro) sequer tem chances de se defender. Por parte do agressor é um crime covarde e sorrateiro, porque atinge as pessoas indistinta e indiretamente, tirando-lhes não a vida, mas as condições e o direito de viver.

Com a destruição da natureza destrói-se o quadro das relações de reconhecimento indispensável para a manutenção da própria vida em sua totalidade. Não afeta apenas a integridade de um ou mais indivíduos, mas a integridade dos seres humanos em seu conjunto, impedidos que ficam da vida, substrato de qualquer reconhecimento. Nas palavras de Leff (2010, p. 21):

[não é possível] garantir o bem como uma ética isolada de uma compreensão
renovada do mundo, do real, do saber, da razão. A crise do mundo é uma
crise moral e do conhecimento que apela para a ética, que põe em jogo um
processo estratégico de reapropriação do mundo e da natureza que reativa a
relação entre o real, o simbólico e o imaginário.

A estratégia moderna, reduzida à produção e transmissão do conhecimento para a gestão racional do meio ambiente, se coloca, agora, como uma questão moral de reconhecimento e de reapropriação do mundo. Talvez, se deva avançar um passo além e alcançar um novo patamar em que se reconhece o direito em si da natureza de ser respeitada independente de sua relação com o ser humano. Mas isso, talvez, ainda seja futurologia.

O que é mais assustador e contraditório, hoje, é que os mecanismos de agressão se tornam sistêmicos, ou seja, acontecem de forma naturalizada no interior de um sistema que se autojustifica e age, por assim dizer, no modo automático, independente da decisão de indivíduos ou grupos. Por essa razão, os indivíduos não são nem podem ser culpabilizados, simplesmente porque, de efeito, lhes cabe o álibi da ignorância e mesmo da impotência. O sistema se impõe por si mesmo, razão pela qual as correções de rumo já não podem ser alcançadas pela ética individualista que não afeta o sistema. Ora, esse é, geralmente, o enfoque da educação ambiental. A ciência e tecnologia enveredaram por um caminho que, se não houver mudanças sistêmicas de rumo, condenam a humanidade a sobreviver da destruição da natureza cuja preservação é, contraditoriamente, sua única possibilidade de sobrevivência. Trata-se, então, de um problema civilizatório. As agressões à natureza, nas proporções que vêm ocorrendo, destroem as condições de vida de qualquer comunidade futura. 
Assim entendida, educação ambiental tem como importante função a formação de uma nova consciência que tenha por base um novo sistema referencial epistêmico, ético e estético da vida planetária como um todo. O sujeito monológico, armado de ciência e tecnologia e confrontado com a natureza, é a metáfora do sujeito confrontado com a própria morte. A liberdade agressiva, conflituosa e sem limites está ligada à certeza antecipada de sua própria morte. Compete ao homem a consciência não só da finitude da natureza, mas, também, da própria finitude. Só com a antecipação desse pensamento, pode-se restabelecer a relação existencial com o ambiente.

Embora não sendo possível falar da natureza como um sujeito com o qual o ser humano interage, constituindo-se como sujeito (HONNETH, 2011 p.86), é legítimo dizer que a natureza exige reconhecimento como condição comum, presente e futura, da vida. Se a relação entre o ser humano e a natureza for entendida simplesmente como um ato unilateral de posse, de domínio e exploração, então os próprios seres humanos podem ser excluídos. Não apenas porque a natureza se vinga das agressões sofridas, como sugere a imagem antropomórfica popular, mas porque o próprio ser humano, na sua incontrolada vontade de domínio, poder e exploração, suprime o contexto de relação, ou seja, sua própria condição de sobrevivência.

Nesse sentido, pode-se dizer que na estrutura da relação homem-natureza está inscrita, como condição de sobrevivência, a disposição do respeito e do reconhecimento. Destruindo a natureza o homem destrói a si mesmo. A relação agressiva do homem com a natureza aniquila a própria relação e, com isso, o próprio ser humano que dela necessita como condição de existência. Assim, o ato de posse e destruição agressiva retorna como efeito bumerangue, transformando o que se afigurava ao ser humano como vitória e vida, em derrota e morte. Adorno e Horkheimer (1985, p.46) escrevem que "a adaptação ao poder do progresso envolve o progresso do poder, levando sempre de novo àquelas formações recessivas que mostram que não é o malogro do progresso, mas exatamente o progresso bem-sucedido que é culpado de seu próprio oposto. A maldição do progresso irrefreável é a irrefreável regressão".

No seu livro "Princípio esperança", Hans Jonas (1984, p.11) diz que "o finalmente liberado Prometeu ao qual a ciência confere forças antes desconhecidas e a ciência impulsos imprevisíveis clama por uma ética capaz de evitar livremente que seu poder venha tornar-se a desgraça do ser humano."

O ponto de partida de tal ética é evitar que a promessa de salvação pela técnica moderna reverta em ameaça ou que a ameaça se torne inseparável da salvação pela técnica. Jonas explica que nenhuma ética tradicional nos informa sobre as normas que as novas modalidades de poder e suas futuras inovações devem respeitar.

O terreno novo da práxis coletiva que pisamos com as novas tecnologias é, para a teoria ética, um terreno inexplorado. Não sabemos o que nos poderia servir de bússola para nossas decisões. Para Jonas, a primeira indicação pode chegar a nós a partir dos preanunciados riscos: "Os raios que riscam o céu do futuro na antevisão de sua dimensão planetária de decadência humana nos permitem entrever princípios éticos dos quais se pode derivar as obrigações do novo poder" (JONAS, 1984, p.7). Segundo esse autor, se trata de uma ética não restrita à normatização do agir quotidiano, mas aberta à dimensão metafísica, envolvendo as razões porque o ser humano tem que se preocupar e garantir o futuro da humanidade.

Trata-se de uma ética que não se limita mais ao âmbito intra-humano. As novas obrigações, assim afirma Jonas (1984), podem ser resumidas no conceito de responsabilidade. Os riscos extremos da aventura tecnológica nos obrigam a assumir, 
também, o risco da consciência de que as obrigações ultrapassam os limites dos valores intersubjetivos e devem se ancorar, de ora em diante, no ser como um todo. Até o momento, a ética se preocupava apenas com a qualidade moral das decisões e dos atos momentâneos, sem perder tempo com o futuro incerto. Mas "com o desenvolvimento do nosso poder a essência do agir humano mudou; e, como a ética trata do agir humano, a consequência é que a natureza mudada do agir humano requer, também, uma mudança da ética" (JONAS, 1984, p. 15).

A natureza qualitativamente nova de muitas de nossas ações nos defronta-se com novas significâncias não presentes nas perspectivas e cânones da ética tradicional. Uma dessas questões é como e em que medida as novas técnicas incidem sobre a natureza, afetando não só as condições, mas, eventualmente, também a própria possibilidade de vida das gerações futuras. Tal possibilidade afeta profundamente a responsabilidade, um dos conceitos centrais da ética. A responsabilidade na ética tradicional sempre se restringia ao espaço das coisas mutantes, nas quais o homem podia intervir. A natureza era a ordem permanente e imutável, livre, portanto, das intervenções humanas e, por isso, externa à responsabilidade humana. A techne, a intervenção técnica sobre a natureza não feria a sua integridade. Por isso, a ação humana sobre a ordem natural não representava um âmbito de significado da ética.

De outra parte, a ética tradicional era antropocêntrica, porquanto dizia respeito apenas às relações intra-humanas. A humanidade era considerada essência imutável, ela própria arredia a qualquer intervenção (techne) humana e regida por desígnios externos. Natureza e humanidade, embora sempre tangentes, existiam, de certo modo, como blocos autônomos, ou seja, com nomoi próprios e independentes. A ética estava inteiramente voltada ao aqui e agora, às oportunidades que as relações ofereciam, restringindo-se ao bom ou mau manejo das relações entre os seres humanos. O que é bom ou mau se decidia no espaço e tempo da efetiva inter-relação humana. Nesse sentido, ninguém podia ser responsabilizado pelos efeitos inesperados ou futuros de suas ações. Nas palavras de Jonas (1984, p.28), "nenhuma ética tradicional tinha como condição o respeito à vida futura da humanidade, ou seja, a existência da espécie". Como se sabe, com o extraordinário poder de intervenção do ser humano sobre o meio ambiente com o surgimento e fantástica expansão da ciência e tecnologia, a situação mudou radicalmente.

Sob o signo da tecnologia, a ética tem a ver com a amplitude ímpar de futuro, provida apenas de saberes provisórios e incertos a respeito de eventos com efeito de longo prazo e, possivelmente, irreversíveis. Por isso, a responsabilidade com relação ao futuro deve tornar-se uma nova dimensão da ética.

Ao contrário das utopias idealistas tradicionais, que se nutriam de um conceito de liberdade desimpedido de qualquer compromisso com o futuro da natureza e, nesse sentido, com o futuro da humanidade como um todo, o conceito de responsabilidade, na sua formulação mais recente, se reveste de uma dimensão humanitária e civilizatória. Encontramo-nos, portanto, às voltas com um novo e mais restrito conceito de liberdade que se confronta com um dos maiores devaneios da modernidade: a liberdade sem limites. Esse é um dos maiores desafios da ética contemporânea em meio à dualidade da liberdade humana que, de um lado, não pode ser impedida de transformar o meio, mas que, de outro, deve evitar o uso inadequado de seu poder. Trata-se do desafio de encontrar respostas à pergunta a respeito das novas obrigações do ser humano no cenário dos complexos e arriscados rumos da ciência e tecnologia. 
Ninguém sabe se um novo Prometeu trará uma nova dádiva, uma nova luz roubada de Zeus. Alguns colocam a esperança na energia do sol; outros, na energia dos ventos; ainda outros num super-regenerador capaz de transformar materiais férteis em materiais físseis. Por enquanto, uma única estratégia se impõe como incontornável: a conservação geral bem planificada. Mas isso não será possível apenas pela intervenção na ponta final do processo todo. É preciso mudar no essencial: "Assim, mesmo que o homo sapiens sapiens possa compreender o que tem de fazer para a sua salvação ecológica, sua natureza o impede de seguir o conselho da sabedoria. Com certeza há uma crise de energia, mas, ao que parece, a verdadeira crise é a crise da sabedoria humana" (GEORGESCU-ROEGEN, 2012, p.180).

É preciso retornar à clássica questão a respeito da diferença, dos limites e propriedades do homo faber e do homo sapiens. É preciso perguntar se o predomínio da techne, da racionalidade instrumental sobre o pensamento e a sabedoria é o caminho ideal ou mesmo o único caminho para a humanidade alcançar seu objetivo da boa vida? A técnica, com seu febril ativismo de superação com sempre novas e mais eficientes formas de domínio sobre as coisas e sobre os próprios homens, inverteu a relação entre o homo sapiens e o homo faber que, de servo, passou a senhor. Ciência e tecnologia assumem extrema relevância ética na medida em que ela tomou conta do pensamento, da vida interior e do sentido humano. Para finalizar, lembro, mais uma vez, Adorno e Horkheimer (1985, p.51, 129): “ [com] a vitória da razão tecnológica sobre a verdade, o pensamento é ele próprio massacrado e despedaçado e com o abandono do pensamento (...) o esclarecimento abdicou de sua própria realização". Reverter essa situação é o sentido mais profundo da educação ambiental.

\section{Referências}

ADORNO, T.; HORKHEIMER, M. Dialética do esclarecimento. Rio de Janeiro: Jorge Zahar, 1985.

BECK, U. La sociedade del riezgo - em busca de la seguridad perdida. Barcelona: Editorial Paidós, 2008.

BOFF, L. Saber cuidar - ética do humano - compaixão pela terra. Petrópolis: Vozes, 1999.

GEORGESCU-ROEGEN, N. Decrescimento - entropia, ecologia, economia. São Paulo: Editora Senac, 2012.

GRINEWALD, J.; RENS, I. Prefácio. In: Georgescu-Roegen, Nicholas. Decrescimento entropia, ecologia, economia. São Paulo: Editora Senac, 2012.

HENRY, M. A barbárie. São Paulo: Realizações Editora, 2012.

HONNETH, A. La Sociedade de desprecio. Madrid: Editorial Trotta, 2011.

HONNETH, A. Luta por reconhecimento - a gramática moral dos conflitos sociais, São Paulo: Editora 34, 2003.

JAHR, F. Bio-Ethik. Eine Umschau über die ethischen Beziehungen des Menschen zu Tier und Pflanze, Kosmos. Münter: Handweiser für Naturfreunde, 1927. 
JONAS, H. Das Prinzip Verantwortung - Versuch einer Ethik für die technologische Zivilisation. Frankfurt am Main: Suhrkamp, 1984.

JOSAPHAT, C. Ética mundial - esperança da humanidade globalizada. Petrópolis: Vozes, 2010.

LEFF, E. Epistemologia ambiental. São Paulo: Cortez Editora, 2010.

LEFF, E. (Coord.). La complejidad ambiental. Buenos Aires: Siglo Veintiuno, 2003.

LOVELOCK, J. Gaia: alerta final. Rio de Janeiro: Intrínseca, 2010.

MORIN, E. A via para o futuro da humanidade. Rio de Janeiro: Bertrand Brasil, 2013.

ZIZEK, S. Vivendo no fim dos tempos. São Paulo: Boitempo Editorial, 2012.

Artigo submetido em 20/11/2013

Artigo aprovado em 20/02/2014 